\title{
Graphical and computational methods for determining the stability constants of mono- and polynuclear complexes with a common intersection point of the family of formation curves
}

https://doi.org/10.21698/rjeec.2020.210

Proceedings Paper

\author{
IGOR POVAR, OXANA SPINU, BORIS PINTILIE
}

Institute of Chemistry, 3 Academiei, 2028, Chisinau, Republic of Moldova

Corresponding author (e-mail): ipovar@yahoo.ca

\begin{abstract}
Aqueous polynuclear systems have been analyzed, for which the family of formation curves intersects at a common point. The analyzed graphical and computational method for determining the stability constants can be used as initial values within the iterative calculation process. In some cases, the stability constants are calculated using only the coordinates of the common intersection point. The obtained equations could be of special interest when the experimental data can be interpreted in several models. In these cases, given the large volume of experimental data, the calculation is simple and the model can certainly be chosen with high safety. The obtained equations may also be applied for critical evaluation of tabular data if the coordinates of the intersection point are known. A series of real polynuclear systems have been analyzed and useful conclusions have been made.
\end{abstract}

Keywords: chemical model of equilibrium, chemical species, formation curve, polynuclear complex, stability constant

\section{INTRODUCTION}

At present, for the determination of the chemical equilibrium model, specially developed programs using modern computing techniques are used. However, despite the existing belief that the methods for determining the number, composition, and stability of species formed in the equilibrium system, in which several complex compounds of arbitrary composition are formed simultaneously, are studied well enough, in some cases to solve this task. Certain difficulties arise. First, in the case of the formation of several complex compounds, it is difficult to predict the model in the first approximation. Second, as a result of the computerized search, several models with values close to the minimum deviation squares are obtained [1-3]. The plurality of solutions to this problem, e.g. lack of a single solution, occurs when the existing information is insufficiently complete.

As examples of the systems with an extremely large number of species formed, "core-link" complexes can serve, where they can vary within wide limits of integer values. For some series of these complexes [4-6], the mathematical processing of the experimental data and the computerized calculation of the equilibrium model are impossible without preliminary information on the composition of the complexes. This information can be obtained through functional transformations of experimental data in the form of additional concentration functions and their derivatives [7-9]. At the same time, in the presence of a vast volume of experimental data, in case of their uniform distribution, along with the graphic processing, it is necessary to use numerical analysis methods $[10,11]$.

In this paper, the polynuclear systems are analyzed, for which the family of curves intersects at a point. The theoretical analysis of the correlation between the position of the intersection point and the composition of the complexes has been the subject of discussion in a series of papers [12-18]. The authors [1214] found a criterion for the appearance of the real and the apparent intersection point. It has been shown that there are two conditions for the appearance of the real intersection point: (a) the derivative of the formation function in respect to the total concentration of one of the components under the invariability conditions for the second component must be zero and (b) the sign of these variables change as they pass through the common point of 
intersection. In the present work, to demonstrate the significance of the derived earlier expressions, a series of real important systems have been taken into consideration.

\section{EXPERIMENTAL PART}

It has been examined the systems, in which reactions with the formation of mononuclear complexes $M L_{n}$ and polynuclear complexes

$M_{q} L_{p}$ take place according to the general scheme:

$$
\begin{array}{ll}
M+n L=M L_{n}, & (n \in Z, n>0) \\
p M+q L=M_{p} L_{q}, & (q, p \in Z, q \geq 1, p>0)
\end{array}
$$

These two types of reactions are described by the following equilibrium constants:

$$
\beta_{n}=\frac{\left[M L_{n}\right]}{[M][L]^{n}}, \quad \beta_{q p}=\frac{\left[M_{q} L_{p}\right]}{[M]^{q}[L]^{p}} .
$$

where $[M]$ and $[L]$ denote the equilibrium concentrations of the metal ion and ligand, correspondingly.

$$
f_{n}=\frac{\left[M L_{n}\right]}{C_{M}}=\frac{\beta_{n}[M][L]^{n}}{C_{M}}, f_{p q}=\frac{q\left[M_{q} L_{p}\right]}{C_{M}}=\frac{\beta_{p q}[M]^{q}[L]^{p}}{C_{M}}
$$

In a previous paper [18], the authors showed that the derivative of the formation function $Z$ with respect to the total (analytical)

$$
\left(\frac{\partial Z}{\partial \ln C_{M}}\right)_{[L]}=\frac{\sum_{q=1} \sum_{p=1} p f_{q p}}{\sum_{q=1} \sum_{p=0} q f_{q p}}-\sum_{q=1} \sum_{p=1} \frac{p}{q} f_{q p},
$$

For these systems at the common intersection point with the coordinates $(Z, \quad-\log [L])$ derivative $\left(\partial Z / \partial \ln C_{M}\right)_{[L]}=0$. The expression

$$
\frac{\sum_{q=2} \sum_{p=1} p f_{q p}-\sum_{q=2} \sum_{p=1} \frac{p}{q} f_{q p}}{\sum_{q=1} \sum_{p=1}(q-1) f_{q p}}=Z
$$

It allows to demonstrate that there are three distinct classes of polynuclear systems, for which the formation function $Z$ does not depend

System 1. Initially, a system, in which a series of mononuclear complexes $M L, M L_{2}, \ldots, M L_{N}$ and one polynuclear complex $M_{P} L_{Q}$ are

$$
\begin{aligned}
& Z=\frac{P}{Q} \\
& P\left(1+\sum_{n=1} \beta_{n}[L]^{n}\right)=Q \sum_{n=1} n \beta_{n}[L]^{n} \\
& \beta_{Q^{P}}=\frac{P C_{M}-Q \sum_{n=1} n \beta_{n}[M][L]^{n}}{P Q[M]^{Q}[L]^{P}}
\end{aligned}
$$

When a single complex $M L_{N}$ is formed, the
The partial molar fractions $f_{n}$ and $f_{p q}$ for mononuclear and polynuclear complexes respectively may be written as

concentration of the metal ion $M$ can be expressed by the partial molar fractions $f_{p q}$ as follows:

obtained for the formation function at this intersection point is:

on the equilibrium concentration $[M]$, therefore the conditions for the real intersection point are met [18].

simultaneously formed, is analyzed. For this system, based on Eq. (4), the following relations may be obtained [18]:

following expressions are valid: 


$$
\begin{aligned}
& \log \beta_{N}=\log P-\log (Q N-P)-N \log [L] \\
& \log \beta_{Q P}=\log \left(C_{M}-[M] \frac{Q N}{Q N-P}\right)-\log Q-\log [M]-P \log [L]
\end{aligned}
$$

Thus, if the coordinates of the intersection point $(P / Q ;-\log [L])$ and $[\mathrm{M}]$ for $C_{M}=$ const are known, the stability constants of the complexes

System 2. A series of mononuclear complexes and a series of polynuclear complexes $M_{p} L_{q}$, $\left(M_{p} L_{q}\right)_{2}, \ldots,\left(M_{p} L_{q}\right)_{x}$ are formed, where $x \in Z, x$ $>$ 1. From Eq. (4), at the intersection point, it results $Z=p / q$. The stability constants of mononuclear complexes are interdependent

$$
\begin{aligned}
& \log \beta_{n}=-\log [L]+\log Z-\log (n-Z) \\
& q \beta_{q p}[M]^{q}[L]^{p}+q \beta_{q p}[M]^{q x}[L]^{p x}+\frac{n q}{n q-p}[M]=C_{M}
\end{aligned}
$$

Therefore, if the coordinates of the common intersection point are known, then from the Eq. (10) the complex stability constant is easily calculated. The stability constants of the

System 3. A series of mononuclear complexes and a series of polynuclear complexes $M_{Q} L_{P}$ are

$$
\begin{aligned}
Z_{\text {mono }}= & \frac{\sum_{n=1} n \beta_{n}[L]^{n}}{1+\sum_{n=1} \beta_{n}[L]^{n}} \\
Z_{\text {poly }}= & \frac{\sum_{p=1} p \beta_{Q p}[L]^{p}}{Q \sum_{n=1} \beta_{Q p}[L]^{p}}
\end{aligned}
$$

polynuclear complexes $M_{q} L_{p}$ and $M_{Q} L_{P}$ can be calculated by solving the system from two equations (11) for two values different $C_{M}$.

formed, where $Q=$ const, $Q, p \in Z, p>0$. From Eq. (4) the following expressions are obtained:

Thus, for this system, the value of the formation function $Z$ at the intersection point depends on both the composition and the stability of the formed complexes. If only one mononuclear complex is formed, its stability constant is

$$
\log \beta_{Q s}-\log \beta_{Q p}=-(p-s) \log [L]+\log (Q Z-p)-(s-Q Z)
$$

In all the analyzed examples, the value $[L]$ depends only on the composition of the formed complexes and on the stability of the

\section{RESULTS AND DISCUSSION}

To elucidate the concrete practice of the above expressions, some real polynuclear systems

\section{Germanic acid and polygermanates}

Previously it was obtained a family of the titration curves $\mathrm{pH}$ versus the number $\mathrm{OH}^{-}$ added per $G e$ for different total germanium mononuclear complexes. The $Z$ value is a function of the stability constants of the

have been analyzed.

concentration $C_{G e}$, which were intersected at the point $(0.6 ; 8.8)$ [16]. These data were interpreted as evidence for the species $\mathrm{H}_{2} \mathrm{GeO}_{3}$, complexes only for the last considered system. 
$\mathrm{HGeO}_{3}^{-}, \mathrm{GeO}_{3}^{2-}, \mathrm{H}_{2} \mathrm{Ge}_{5} \mathrm{O}_{11}, \mathrm{HGe}_{5} \mathrm{O}_{11}^{-}$and

$\mathrm{Ge}_{5} \mathrm{O}_{11}^{2-}$. For the quantitative description of the

$$
\begin{aligned}
& \mathrm{Ge}(\mathrm{OH})_{4}+\mathrm{OH}^{-}=\mathrm{GeO}(\mathrm{OH})_{2}^{-}, \quad \beta_{1} \\
& \mathrm{Ge}(\mathrm{OH})_{4}+2 \mathrm{OH}^{-}=\mathrm{GeO}_{2}(\mathrm{OH})_{2}^{2-}, \quad \beta_{2} \\
& 8 \mathrm{Ge}(\mathrm{OH})_{4}+3 \mathrm{OH}^{-}=\left(\mathrm{Ge}(\mathrm{OH})_{4}\right)_{8}(\mathrm{OH})_{3}^{3-}, \quad \beta_{38}
\end{aligned}
$$

equilibria in this system the authors [16] used the following model:
The graphical data $Z=f(p H)$ of the work [16] plotted for different total germanium concentration $C_{G e}$, (Fig. 1) show an intersection point at $Z \approx 0.36$ and $\mathrm{pH}=4.92$, that is a clear indication for the formation of certain polynuclear complexes. Our analysis of possible mononuclear and polynuclear species by the Eq. (4)-(7) indicated that by adding $\mathrm{OH}^{-}$to $\mathrm{Ge}(\mathrm{OH})_{4}$ solutions the anions $\mathrm{GeO}(\mathrm{OH})_{3}^{-}, \mathrm{GeO}_{2}(\mathrm{OH})_{2}^{2-}$ and $\left.\left(\mathrm{Ge}(\mathrm{OH})_{4}\right)_{8} \mathrm{OH}\right)_{3}^{3-}$ are formed. The assumption that other species, $G e_{5} O_{11}^{2-}$ and
$\mathrm{HGe}_{7} \mathrm{O}_{16}^{3-}$ should be formed, was tested. It was found that neither of them could explain the data [16]. By applying Eq. (5) to the $Z$ value at the intersection point, if only one polynuclear complex is present, the formation of the following complexes $\left(\mathrm{Ge}(\mathrm{OH})_{4}\right)_{Q}\left(\mathrm{OH}^{-}\right)_{P}$ is possible: $\left(\mathrm{Ge}(\mathrm{OH})_{4}\right)_{8}\left(\mathrm{OH}^{-}\right)_{3} \quad\left(\mathrm{Ge}(\mathrm{OH})_{4}\right)_{11}\left(\mathrm{OH}^{-}\right)_{4}$, $\left(\mathrm{Ge}(\mathrm{OH})_{4}\right)_{14}\left(\mathrm{OH}^{-}\right)_{5}$ and so on. Using Eq. (6) for the $\left(\mathrm{Ge}(\mathrm{OH})_{4}\right)_{8}\left(\mathrm{OH}^{-}\right)_{3}$ complex, one obtains:

$$
\beta_{2}=\frac{3-5 \beta_{1}\left[\mathrm{OH}^{-}\right]}{13\left[\mathrm{OH}^{-}\right]^{2}}=1.38 \cdot 10^{6} ; \quad \log \beta_{2}=6.14,
$$

e.g. the same value as in paper [16]. For other possible complexes at the intersection point $(0.36 ; \quad 4.92), \quad\left(\mathrm{Ge}(\mathrm{OH})_{4}\right)_{11}\left(\mathrm{OH}^{-}\right)_{4} \quad$ and $\left(\mathrm{Ge}(\mathrm{OH})_{4}\right)_{14}\left(\mathrm{OH}^{-}\right)_{5}$, Eq. (6) gives the negative

$$
\beta_{1}=\frac{3-13 \beta_{2}\left[\mathrm{OH}^{-}\right]^{2}}{5\left[\mathrm{OH}^{-}\right]}=4.75 \cdot 10^{4} ; \quad \log \beta_{1}=4.69,
$$

which is very close to the value found in [16], $\log \beta_{1}=4.68$. The applying Eq. (6) to other possible complexes $\left(\mathrm{Ge}(\mathrm{OH})_{4}\right)_{11}\left(\mathrm{OH}^{-}\right)_{4}$ and

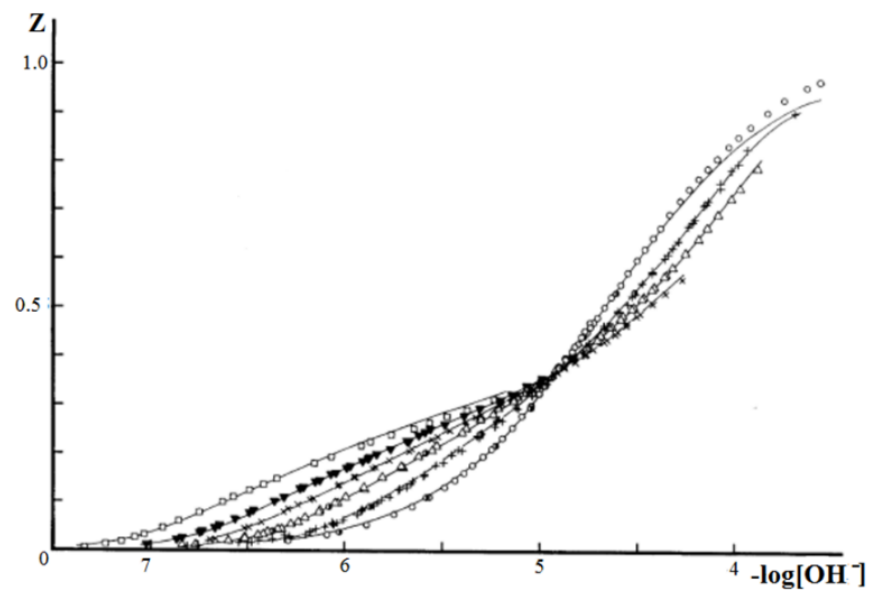

Fig. 1. Experimental data plotted as curves, $Z\left(\log \left[\mathrm{OH}^{-}\right]\right)_{C_{G e}}, t=25^{\circ} \mathrm{C}$ at $C_{G e}=0.040,0.030,0.025$ and $0.020 \mathrm{~mol} / \mathrm{L}[16]$ 
$\mathrm{Zn}^{2+}$ - 2-mercaptopropionic acid (thiolactic acid, TLA) system

The formation curves obtained by Brabander et mixture of polynuclear and mononuclear al. [19] for this system where $C_{Z n}$ was varied from 0.002 to $0.032 \mathrm{~mol} / \mathrm{L}$ have a common intersection point $(Z ;-\log [L])_{C_{Z n}}$ with the coordinates $(1.33 ; 6.91)$ (Fig. 2). The presence complexes. In Table 1 three equilibrium models, used by the authors [19] for the system $\mathrm{Zn}^{2+}-T L A$, are shown for computer analysis of the experimental data.

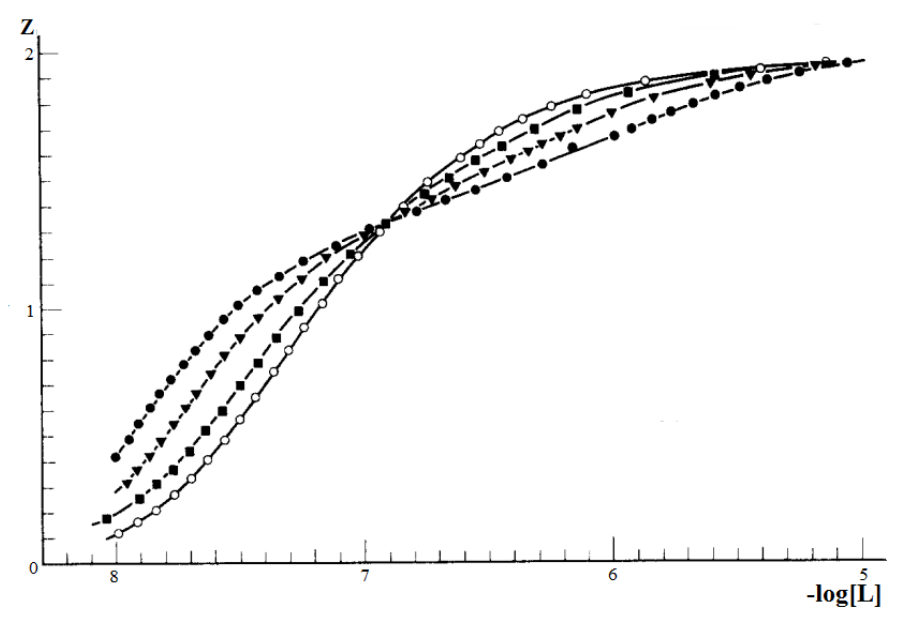

Fig. 2. Formation curves for the $Z n^{2+}-T L A$ system [19]

Table 1. The equilibrium models in the $Z n^{2+}$ - thiolactic acid system [19]

\begin{tabular}{c|cc}
\hline Model number & Species & Stability constant \\
\hline \multirow{2}{*}{ I } & $Z n L_{2}$ & 14.30 \\
& $Z n_{3} L_{4}$ & 34.92 \\
II & $Z n L_{2}$ & 14.32 \\
& $Z n_{3} L_{4}$ & 34.78 \\
III & $Z n_{2} L_{2}$ & 17.29 \\
& $Z n L$ & 6.85 \\
& $Z n L_{2}$ & 14.34 \\
& $Z n_{3} L_{4}$ & 34.79 \\
\hline
\end{tabular}

For model III, Eq. (6) takes the form:

$$
4\left(1+\beta_{1}[L]+\beta_{2}[L]^{2}\right)=3\left(\beta_{1}[L]+2 \beta_{2}[L]\right),
$$

from which one can obtain

$$
\begin{aligned}
& \beta_{1}=\frac{2 \beta_{2}[L]^{2}-4}{[L]}=\frac{2 \cdot 10^{14.34} \cdot 10^{(-6.91 \times 2)}-4}{10^{-6.91}}=2.08 \cdot 10^{7} ; \log \beta_{1}=7.31 \\
& \beta_{2}=\frac{\beta_{1}[L]+4}{2 \cdot[L]^{2}}=\frac{10^{6.85} \cdot 10^{-6.91}+4}{2 \cdot 10^{(-6.91 \times 2)}}=1.61 \cdot 10^{14} ; \log \beta_{2}=14.21 .
\end{aligned}
$$

These calculated values are close to those from those tabulated (see Table 1). For the model I the inconsistent value of the stability constant for the mononuclear complex $Z n L_{2}$ was obtained. Therefore, this model must be discarded. Consequently, now it is possible to choose between model II and model III.
Unfortunately, if at the common intersection point two polynuclear complexes of the composition $Z n_{3} L_{4}$ and $Z n_{2} L_{2}$ are formed, this point is not a real one $[12,13]$ and the derived equations (4)-(14) are not applicable for this model. 
Mono- and polynuclear hydroxocomplexes of the dimethyltin(IV) ion in aqueous solution

The hydroxocomplexes of the dimethyltin (IV) ion were studied in solutions with $\left[\mathrm{ClO}_{4}{ }^{-}\right]=$ $3.00 \mathrm{~mol} / \mathrm{L}$ by e.m.f. measurements of $\left[\mathrm{H}^{+}\right]$ [20]. Figure 3 gives the data $Z\left(-\log \left[\mathrm{H}^{+}\right]\right)$with the total dimethyltin(IV) concentration as a parameter as calculated from the e.m.f. data. The system exhibits a common intersection point at $Z$ of about 1.43 and $-\log \left[\mathrm{H}^{+}\right]=5.5$. The existence of this common point indicates that the degree of polymerization of the system is a maximum at this $\mathrm{pH}$ and the further addition of
$\mathrm{OH}^{-}$converts the polymeric species to monomeric or at least to polymeric species with lower degrees of polymerization and with higher ligand-metal ratios. Throughout the entire range of the data, $1.0 \leq \mathrm{pH} \leq 8.0$, the measurements were explained only by assuming the formation of five complexes [20], according to the hydrolysis reactions (the notation $\left(\mathrm{CH}_{3}\right)_{2} \mathrm{Sn}^{2+} \equiv \mathrm{M}^{2+}$ is used):

$$
\begin{aligned}
& \mathrm{M}^{2+}+\mathrm{H}_{2} \mathrm{O}=\mathrm{MOH}^{+}+\mathrm{H}^{+}, \quad \log \beta_{11}=-3.45 \\
& \mathrm{M}^{2+}+2 \mathrm{H}_{2} \mathrm{O}=\mathrm{M}(\mathrm{OH})_{2}+2 \mathrm{H}^{+}, \quad \log \beta_{12}=-9.00 \\
& 2 \mathrm{M}^{2+}+2 \mathrm{H}_{2} \mathrm{O}=\mathrm{M}_{2}(\mathrm{OH})_{2}^{2+}+2 \mathrm{H}^{+}, \quad \log \beta_{22}=-4.70 \\
& 2 \mathrm{M}^{2+}+3 \mathrm{H}_{2} \mathrm{O}=\mathrm{M}_{2}(\mathrm{OH})_{3}^{+}+3 \mathrm{H}^{+}, \quad \log \beta_{23}=-9.80 \\
& 3 \mathrm{M}^{2+}+4 \mathrm{H}_{2} \mathrm{O}=\mathrm{M}_{3}(\mathrm{OH})_{4}^{2+}+4 \mathrm{H}^{+}, \quad \log \beta_{23}=-10.30
\end{aligned}
$$

If one supposes that in this system four complexes are formed in significant quantities,

$$
\begin{aligned}
& Z_{\text {mono }}=\frac{\beta_{11}\left[H^{+}\right]^{-1}+2 \beta_{12}\left[H^{+}\right]^{-2}}{1+\beta_{11}\left[H^{+}\right]^{-1}+\beta_{12}\left[H^{+}\right]^{-2}}=1.45 \\
& Z_{\text {poly }}=\frac{2 \beta_{22}\left[H^{+}\right]^{-2}+3 \beta_{23}\left[H^{+}\right]^{-3}}{2\left(\beta_{22}\left[H^{+}\right]^{-2}+\beta_{23}\left[H^{+}\right]^{-3}\right.}=1.36
\end{aligned}
$$

As can be seen, the obtained values are close to the formation function value at the intersection point, $\mathrm{Z}=1.44$. To obtain a more exact value for $Z_{\text {poly }}$, perhaps, it is necessary to consider the formation of the polynuclear complex

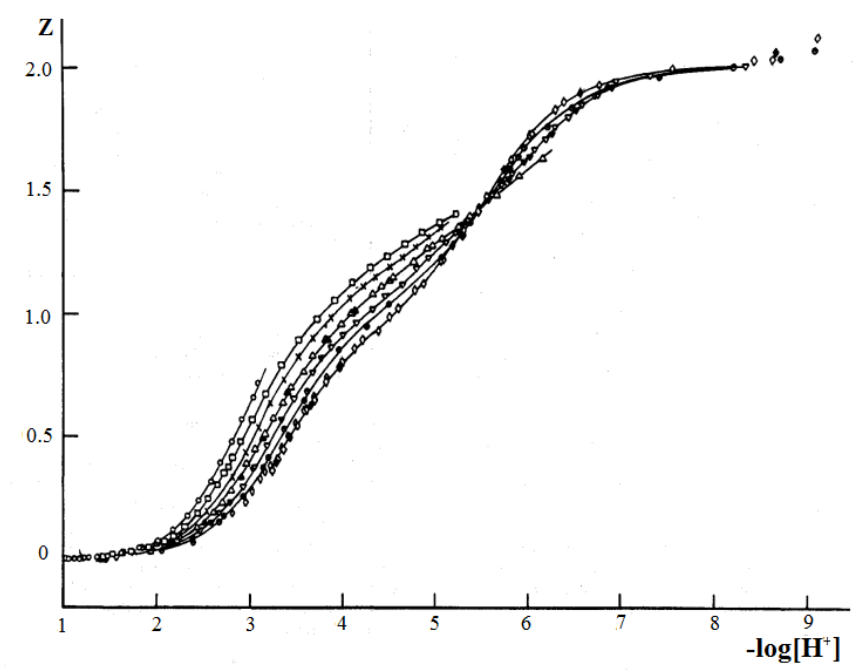

Fig. 3. The average number of $\mathrm{OH}^{-}$bound per dimethyltin(IV), $\mathrm{Z}$, as a function of $-\log \left[\mathrm{H}^{+}\right]$for the values of the total $\left[\left(\mathrm{CH}_{3}\right)_{2} \mathrm{Sn}^{2+}\right]$ from $1 \times 10^{-3} \mathrm{~mol} / \mathrm{L}$ to $8 \cdot 10^{-2} \mathrm{~mol} / \mathrm{L}$ [20] 
Mono- and polynuclear species in system $\mathrm{B}(\mathrm{OH})_{3}-\mathrm{H}_{2} \mathrm{O}$

Experimental data obtained by authors [21] in intersect at the point $(0.39 ;-8.8)$. Researchers the form of formation curves are shown in Fig. [21] proposed the following model of equilibria 4. The formation curves $Z=f\left(\log \left[H^{+}\right]\right)_{C_{B}}$ in this system:

$$
\begin{aligned}
& B(\mathrm{OH})_{4}^{-}+H^{+}=B(\mathrm{OH})_{3}+\mathrm{H}_{2} \mathrm{O}, \quad \log K_{11}=9.00, \\
& 3 B(\mathrm{OH})_{4}^{-}+H^{+}=B_{3} \mathrm{O}_{3}(\mathrm{OH})_{5}^{2-}+4 \mathrm{H}_{2} \mathrm{O}, \quad \log K_{31}=11.56, \\
& 3 B(\mathrm{OH})_{4}^{-}+2 \mathrm{H}^{+}=\mathrm{B}_{3} \mathrm{O}_{3}(\mathrm{OH})_{4}^{-}+4 \mathrm{H}_{2} \mathrm{O}, \quad \log K_{32}=20.16 .
\end{aligned}
$$

From Eq. (12) it follows:

$$
Z_{\text {mono }}=\frac{\beta_{1}\left[H^{+}\right]}{1+\beta_{1}\left[H^{+}\right]}=0.39
$$

and

$$
\log \beta_{1}=\log Z-\log \left[H^{+}\right]-\log (1-Z)=-8.98
$$

Consequently, the obtained $K_{11}$ value is hand, Eq. (13) for this system is: practically the same as in [21]. From the other

$$
Z_{\text {poly }}=\frac{\beta_{31}\left[H^{+}\right]+2 \beta_{32}\left[H^{+}\right]^{2}}{3\left(\beta_{31}\left[H^{+}\right]+\beta_{32}\left[H^{+}\right]^{2}\right)}=0.53
$$

Comparing values of $Z_{\text {mono }}$ and $Z_{\text {poly }}$ from Eqs. (17) and (18), one can mention that the first value practically coincides with the experimental one, while the second $\mathrm{Z}$ value differs by 0.14 unit. This discrepancy between the experimental and the calculated values (18), using the assumed values of the stability constants [21], proves that the model (16) has not been self-consistent. One of the reasons might be the absence of some chemical species, as suggested by the authors [21]. However, the alternative set of complexes, including in addition to the model (16) the complex $\mathrm{B}_{4} \mathrm{O}_{4}(\mathrm{OH})_{6}^{2-}$, does not fall within the class of polynuclear systems examined here, because the common point of intersection is apparent.

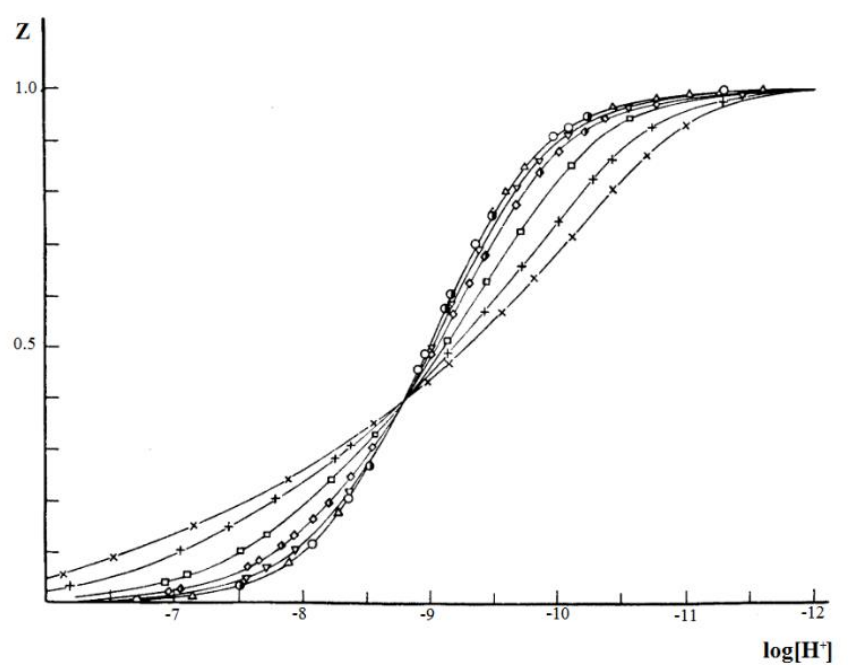

Fig. 4. The average number of $\mathrm{OH}^{-}$bound per boron, $\mathrm{Z}$, as a function of $-\log \left[\mathrm{H}^{+}\right]$at $C_{B}=$ const [21]

\section{CONCLUSIONS}

The common real intersection point in the diagram $Z=f(\log [L])_{C_{M}}$ contains useful information regarding the equilibrium model for the polynuclear systems, e.g. the nature, composition and thermodynamic stability of the mononuclear and polynuclear system. 
The stability constants, calculated with the expressions, derived earlier by one of the authors, can be used as initial values in the iterative calculation process, as well as for the verification of existing tabular data. In some cases, it is possible to calculate the stability constants using only the coordinates of the common real intersection point. The obtained equations are of special interest when the experimental data may be interpreted in several models. In these cases, given a large volume of experimental data, the calculation is simple and the model can certainly be chosen large. As it has been shown above, the obtained equations can also be used for critical

\section{ACKNOWLEDGEMENTS}

The authors would like to express their gratitude to the COST action CA18202 Network for Equilibria and Chemical

\section{REFERENCES}

[1] STUMM, W., MORGAN, J.J. Aquatic chemistry: chemical equilibria and rates in natural waters, John Wiley \& Sons, N.Y., Toronto, 2012, Third Edition, 1040 p.

[2] MARTELL, A.E., HANCOCK, R.D. Metal Complexes in Aqueous Solutions. Modern Inorganic Chemistry, Springer Science \& Business Media, 2013, 254 p.

[3] SCHMIDT, F.K. Optimization methods in chemical thermodynamics and kinetics, Publishing House of Irkutsk University, Irkutsk, 2005, p. 214 p. [In Russian].

[4] LEGGETT, D. J. Computational Methods for the Determination of Formation Constants, Springer Science \& Business Media, 2013, 494 p.

[5] MUTHAIAH, S., BHATIA, A., KANNAN, M. Stability of Metal Complexes, IntechOpen, 2020, doi: 10.5772/intechopen.90894.

[6] GUTTEN, O., RULÍSEK, L. Inorg. Chem., 52, 2013, no. 18, p.10347. doi: 10.1021/ic401037x.

[7] BUTLER, J.N. Ionic Equilibrium: Solubility and $\mathrm{pH}$ Calculations. John Wiley \& Sons, N.Y., 1998, 559 p.

[8] POVAR, I. Zh. Neorg. Khim., 38, no. 11, 1993, p. 1902.

[9] POVAR, I. Zh. Neorg. Khim., 38, , no. 11, 1993, p. 1906. evaluation if the coordinates of the real intersection point are known.

Nevertheless, it should be noted that this approach contains some limitations. Firstly, it is applicable for the determination of stability constants only for chemical species, which are formed under the conditions of the intersection of formation curves. Secondly, the above equations are applicable only for certain models. Thirdly, the experimental data must cover an adequately large range of component concentrations to bypass potential mistakes in interpreting the nature of the common point of intersection.

Thermodynamics Advanced Research for the financial support of this study.

[10] OTT, R., LONGNECKER M. An introduction to statistical methods and data analysis, Cengage Learning, 2008, 1296 p.

[11] WEERAHANDI, S. Exact statistical methods for data analysis. Springer Science \& Business Media, N.Y., 2003, 329 p.

[12] VAN POUCKE, L.G., BRABANDER, H.F. Talanta, 20, no. 8, 1973, p. 733.

[13] VAN POUCKE, L.G., BRABANDER, H.F. Talanta, 21, no. 4, 1974, p. 279.

[14] SANMARTIN, J. et al. Polyhedron, 19, no. 2, 2000, p. 185.

[15] BRABANDER, H.P., VAN POUCKE, L.G., EECKHAUT, Z. Inorg. Chim. Acta, 6, no 3, 1972, p. 459.

[16] INGRI, I., Acta Chem. Scand., 17, no. 3, 1963, p. 597.

[17] TCHAKIRIAN, A., CARPENI, G., Compt. Rend., 226, 1948, p.1094.

[18] POVAR, I. Talanta, 41, no. 8, 1994, p. 1363.

[19] DE BRABANDER, H.F., GEOMINNE, A.M., VAN POUCKE, L.C. J. Inorg. Nucl. Chem., 37, no.3, 1975, p.799.

[20] TOBIAS, R.S., OGRINS, I., NEVETT, B.A. Inorg. Chem., 1, no.3, 1962, p. 638.

[21] INGRI, N.I., LAGERSTROM, G., FRYDMAN, M.I., SILLEN, L.G. Acta Chem. Scand. 11, no.6, 1957, p. 1034. 